\title{
Childhood Nodular Sclerosis Classic Hodgkin Lymphoma
}

National Cancer Institute

\section{Source}

National Cancer Institute. Childhood Nodular Sclerosis Classic Hodgkin Lymphoma. NCI

Thesaurus. Code C8062.

Nodular sclerosis classic Hodgkin lymphoma occurring in childhood. 